\title{
Final Electrode Position in Subthalamic Nucleus Deep Brain Stimulation Surgery: A Comparison of Indirect and Direct Targeting Methods
}

\author{
Mehmet TONGE ${ }^{1,2,3}$, Ersoy KOCABICAK ${ }^{1,2,5}$, Linda ACKERMANS ${ }^{1}$, Mark KUIJF ${ }^{4}$, Yasin TEMEL ${ }^{1,2}$ \\ ${ }^{1}$ Maastricht University Medical Center, Department of Neurosurgery, Maastricht, The Netherlands \\ ${ }^{2}$ Maastricht University Medical Center, Department of Neuroscience, Maastricht, The Netherlands \\ ${ }^{3}$ Istanbul Medipol University, Department of Neurosurgery, Istanbul, Turkey \\ ${ }^{4}$ Maastricht University Medical Center, Department of Neurology, Maastricht, The Netherlands \\ ${ }^{5}$ Ondokuz Mayis University, School of Medicine, Department of Neurosurgery, Samsun, Turkey
}

\section{ABSTRACT}

AIM: High frequency stimulation of the subthalamic nucleus (STN) is nowadays a widely performed surgery for patients with Parkinson's disease (PD). The field has witnessed a shift from indirect targeting to direct targeting. The question arises whether this change has influenced the final electrode position in STN deep brain stimulation surgery. To address this question, we compared the final electrode positions in atlas-based and magnetic resonance-based targeting methods in our series.

MATERIAL and METHODS: We performed a database review of the surgeries performed in three affiliated centers.

RESULTS: We have found that with the shift to direct imaging, three key changes have taken place. The first is that the number of microelectrode recording trajectories has decreased by approximately 1 microelectrode. Secondly, the central trajectory has been chosen as the final position in more patients, and the third change is that direct targeting has improved the laterality of the targeting significantly.

CONCLUSION: Direct targeting has changed routine clinical practice, thereby further refining the surgical approach.

KEYWORDS: Direct targeting, Final lead, Indirect targeting, Parkinson's disease, Subthalamic nucleus

\section{INTRODUCTION}

$\mathrm{H}$ igh frequency stimulation of the subthalamic nucleus (STN) is nowadays a widely performed surgery for patients with Parkinson's disease (PD) $(2,15)$. The longterm therapeutic effects have been documented by numerous clinical studies $(4,8)$. The most prominent determinants of the success of this therapy are the selection of patients and the accuracy of targeting the STN. For the latter, three factors are relevant: stereotactic accuracy, imaging techniques and electrophysiological mapping of the target area $(3,6,24)$.
Stereotactic coordinates derived from stereotactic human brain atlases merged with ventriculography and/or computerized tomography (CT) in combination with microelectrode recording (MER) were the fundamental tools of surgery in early days (indirect targeting) (11,13). Advances in imaging techniques allowed a direct visualization of the target with high-resolution magnetic resonance (MR) imaging in recent years (direct targeting) $(1,16,20,23)$. The field has witnessed a shift from indirect targeting to direct targeting. The question arises whether this change has influenced the choice for the final electrode position in STN deep brain stimulation (DBS) 
surgery. To address this question, we compared the final electrode positions in atlas-based and MR-based targeting methods in our series.

\section{MATERIAL and METHODS}

\section{Design of the Study}

This study is a retrospective database review of the surgeries performed in the Maastricht University Medical Center (MUMC), Ondokuz Mayis University (OMU) hospital and Istanbul Medipol University (IMU) hospital. The DBS programs for movement disorders of OMU and IMU were established in accordance with the MUMC DBS program.

\section{Data Collection}

Medical records of patients with PD undergoing DBS of the STN in the three centers were investigated by three authors independently (MT, EK, and YT). Patient demographics, surgical details, intraoperative electrophysiological findings, and postoperative clinical and radiological data were collected.

\section{Surgical Technique}

Patients with PD were referred to our centers for DBS of the STN. The details regarding patient selection and follow-up have been described before $(6,21)$. The surgeries can be divided in two periods. The first period is from 2003-2011 and the second period is 2012-2014. The surgical techniques in both periods were identical except for the targeting method (Figure $1 A-C)$. In the first period, referred here as group $A$, the targeting was performed indirectly with atlas-based coordinates. The standard coordinates were $11-13 \mathrm{~mm}$ lateral, $2 \mathrm{~mm}$ posterior, and $4 \mathrm{~mm}$ below the mid-commissural point (22). In the second period, referred here as group $\mathrm{B}$, the targeting was performed directly on T2W MR imaging on a 1.5 (OMU) or 3T (MUMC and IMU) scanners. In this group of patients the dorsolateral part of the STN was targeted, as described previously (5). In both periods, MR scanning was performed 1-5 days before surgery; including gadolinium enhanced T1 weighed imaging (slice thickness $1 \mathrm{~mm}$ with no gaps). The T2 axial sequence was added in 2011 (slice thickness $2 \mathrm{~mm}$ with no gaps) to the imaging protocol allowing direct targeting (Figure 1A-C). The trajectory planning was performed on contrast enhanced T1 imaging. On the day of surgery, a stereotactic CT was obtained and a fusion with the MR images was performed (Framelink, Medtronic, Minneapolis, USA) as described by Savas et al previously (16). In principle, 5 microelectrodes were used for neurophysiological mapping of the area, if the trajectory planning allowed this. In the case of the presence of vessels in one or more of these trajectories, we discarded the respective electrode(s). MERs were initiated $10 \mathrm{~mm}$ above the target point and continued $1.0 \mathrm{~mm}$ steps. From $5 \mathrm{~mm}$ above target, steps of $0.25-0.50 \mathrm{~mm}$ were used for MER until STN activity disappeared and/or typical substantia nigra activity appeared. The trajectories with the longest STN activity were chosen for test stimulation. The trajectory with the least side effects and highest effect on the key symptoms with the largest stimulation window (amplitude thresholds of therapeutic and side-effects) was chosen for the final placement of the final electrode $(5,6)$. Postoperatively all patients received either a $\mathrm{CT}$ or MR, and the images were fused.

\section{Statistical Analysis}

The data are presented as mean and standard deviation (SD). An independent samples T test was used to investigate meaningful differences with respect to MER and trajectories. A chi-square test was used to evaluate the differences in the distribution of the final trajectories between groups. A $p<0.05$ was considered significant. All data were analyzed by SPSS version 22.0 (IBM Inc, USA).

\section{- RESULTS}

\section{Demographic Data}

In total, complete surgical data sets from 98 patients were collected. Fifty-seven patients were in group $A$ (indirect targeting period) and 41 patients entered group B (direct targeting period). The mean ages at surgery were $61.4 \pm 9.2$ and $56.4 \pm 9.3$ for groups $A$ and $B$, respectively. The percentage of males were $64.9 \%$ and $56.1 \%$ and females $35.1 \%$ and $43.9 \%$, in groups $A$ and $B$, respectively. All patients received bilateral DBS of the STN except for two in group B.

In the patients of this study, postoperative imaging revealed an adequate electrode position in accordance with the surgical planning.

\section{Trajectories}

In group $A$, in total 469 MER electrodes were used during surgery and in group B, 280 MER electrodes were used. This means that in group A, per STN a mean of $4.1 \pm 0.9$ MER were used. In group B, a mean of $3.4 \pm 0.8$ MER electrodes were used per STN. This difference was statistically significant $(t=5.5, p<0.01)$.

\section{Final Electrode Positions}

In group A, in $53 \%$ of the STN's, the central trajectory was chosen and in group B, in $62 \%$ of the STN's (Table I). This difference did not reach statistical significance. However, the difference between the lateral trajectories, $15 \%$ in group $A$ and $4 \%$ in group $B$, was statistically the most meaningful difference $(p<0.01)$.

\section{Target Coordinates}

Additional analysis of the stereotactic coordinates obtained from direct targeting in group B showed the following parameters from the mid-commissural point were obtained for the target, X: 11.89 (10.4-13.4) $\pm 0.76 \mathrm{~mm}, \mathrm{Y}: 1.74(0.5-3) \pm$ $0.59 \mathrm{~mm}$ and $\mathrm{Z}: 4.0(2-5) \pm 0.79$.

After MER and test stimulation, the implantation coordinates became, X: 12.10 (10-14) $\pm 0.99 \mathrm{~mm}, \mathrm{Y:} 1.94(0-4) \pm 0.94 \mathrm{~mm}$ and $Z: 4$ for group $A$, and $X: 11.76(9.5-13.4) \pm 0.94 \mathrm{~mm}, Y: 2.01$ $(0-5) \pm 1.25$ and $Z: 4.00(2-5) \pm 0.82$ for group $B$.

\section{DISCUSSION}

Here, we addressed the question whether advances in the targeting method, from indirect to direct targeting, has 
influenced the choice for the final trajectory. The indirect targeting method was used between 2003 and 2011 at the main center (MUMC) with the greatest contribution to data pool in this study. MUMC shifted to direct targeting by 2012 . However having the identic technique with MUMC under supervision of the senior author, the other two centers are relatively new and OMU performed mostly the direct targeting method in DBS surgery planning between 2011 and 2014, and IMU between 2013 and 2014. While the atlas-based stereotactic predefined coordinates were used to localize the STN in indirect targeting era, the T2 images were used in recent direct targeting method as described in detail previously $(6,16)$. Our multi-affiliated center retrospective investigation shows that three key changes have taken place. The first is that the number of MER trajectories has decreased by approximately 1 microelectrode. This is an intuitive development, since a better visualization of the target by mainly $\mathrm{T} 2 \mathrm{~W}$ imaging at higher resolution, is likely to result in a more accurate approach, thereby discarding selectively trajectories. One example is that an anterior trajectory can be discarded if the targeting is placed in the dorsal part of the STN as visible on the MR images, thereby still having access to medial, lateral and posterior trajectories, if needed.

The second change is that the central trajectory has been chosen as the final position in more patients. Although this

Table I: This Table Shows the Distribution of the Final Electrode Positions in the Five Possible Trajectories in the Group of Patients Operated on with Indirect Targeting (Group A) and Direct Targeting (Group B).

\begin{tabular}{lcc}
\hline \multirow{2}{*}{$\begin{array}{l}\text { Final electrode } \\
\text { position }\end{array}$} & \multicolumn{2}{c}{ Percentage (\%) } \\
\cline { 2 - 3 } & Indirect targeting & Direct targeting \\
\hline Center & 53 & 62 \\
\hline Anterior & 12 & 10 \\
\hline Medial & 10 & 10 \\
\hline Lateral & 15 & 4 \\
\hline Posterior & 10 & 15 \\
\hline
\end{tabular}

does not reach statistical significance in this investigation, the difference is about $10 \%$ (17). This is again intuitive. With direct visualization of the target, in about two-thirds of the patients the presumed target trajectory becomes also the final trajectory. In other patients, a different trajectory is chosen due to longer STN activity with MER and/or a better therapeutic window. It is known that the boundaries of the STN on the MR do not always correspond with MER. Also the direct visualization of the STN may be challenging in differentiation from SNr, especially on low-resolution images. The posterior border of the STN remains challenging even at 3T MRI (12, 18). In addition, the position of the optimal place might vary per patient (24).

The third change is that the direct targeting has apparently improved the laterality of the targeting, since with adequate T2 weighed imaging the lateral border of the STN and the internal capsule can be visualized accurately. The anatomical variability of the STN is on MR images a known phenomenon $(7,10)$. Here, we found similar variations in the direct targeting group for the presumed target, with ranges of $3.0 \mathrm{~mm}$ for $X$ (10.4-13.4), $2.5 \mathrm{~mm}$ for $Y(0.5-3)$ and $3.0 \mathrm{~mm}$ for the Z-axis (2$5)$, with respect to the mid-commissural point. The anatomical variation of the target within the STN obtained preoperatively is also known to vary $(9,14)$.

A final remark is that in group $B$, the mean age was significantly younger. This a well- known development in the field, already obvious before the publication of the EARLYSTIM study group's results (19), probably due to the increased awareness of the long-term beneficial effects of the treatment, and possibility of adequately management of its complications. However out data pool was collected from three affiliated centers performing the identic DBS surgery discipline, the $\mathrm{MRI}$ devices used for acquiring preoperative targeting images have different Tesla powers. This issue may arise the question of different distortions. We only accepted the total deviation of less than $1 \mathrm{~mm}$ measured on surgical planning software in all our procedures.

\section{CONCLUSION}

With the shift to direct imaging, three key changes have taken

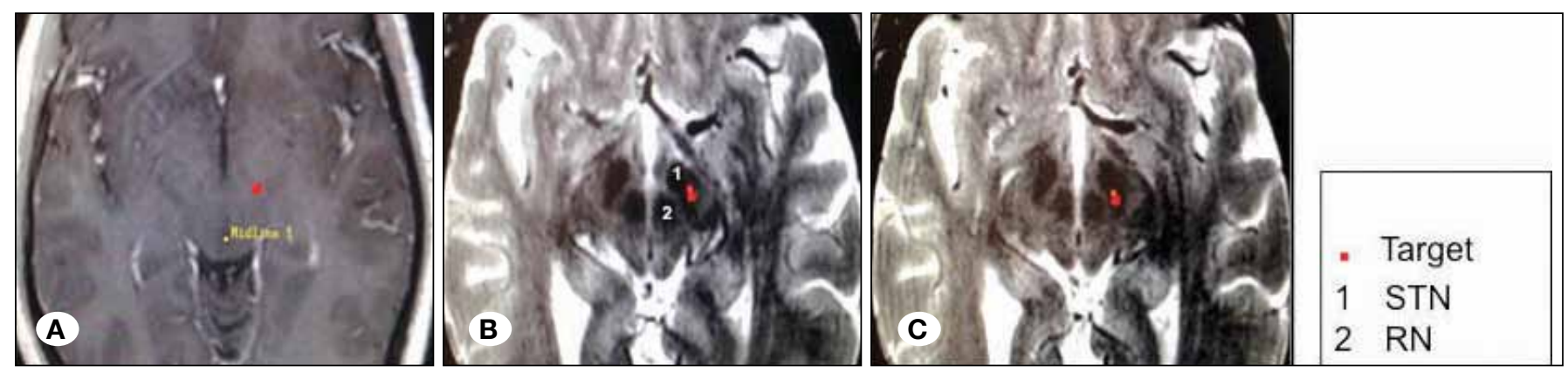

Figure 1: This figure shows $3 \mathrm{MRI}$ images from the planning station (Framelink, Medtronic); A) illustrates the target on a T1 axial MR image in a patient in group $A$ (indirect targeting with the standard coordinates, $x=12, y=-2, Z=-4$, from the midcommissural point), B) shows the target on a T2 axial MR image in a patient operated on with direct targeting (group B), if the standard coordinate were used, and in C) the same image, when direct targeting is performed. Please note the difference between the target with standard coordinates (B) and individually tailored coordinates (C). STN: Subthalamic nucleus, RN: Red nucleus. 
place: the number of MER trajectories has decreased by approximately 1 microelectrode, in more patients the central trajectory has been chosen as the final position, and the third change is that direct targeting has improved the laterality of the targeting significantly.

\section{REFERENCES}

1. Cheng $\mathrm{CH}$, Huang $\mathrm{HM}$, Lin $\mathrm{HL}$, Chiou SM: $1.5 \mathrm{~T}$ versus $3 T \mathrm{TRI}$ for targeting subthalamic nucleus for deep brain stimulation. $\mathrm{Br} \mathrm{J}$ Neurosurg 28:467-470, 2014

2. Eggington S, Valldeoriola F, Chaudhuri KR, Ashkan K, Annoni E, Deuschl G: The cost-effectiveness of deep brain stimulation in combination with best medical therapy, versus best medical therapy alone, in advanced Parkinson's disease. J Neurol 261:106-116, 2014

3. Israel Z, Hassin-Baer S: Subthalamic stimulation for Parkinson's disease. Isr Med Assoc J 7:458-463, 2005

4. Janssen ML, Duits AA, Tourai AM, Ackermans L, Leentjes AF, van Kranen-Mastenbroek V, Oosterloo M, Visser-Vandewalle V, Temel Y: Subthalamic nucleus high-frequency stimulation for advanced parkinson's disease: Motor and neuropsychological outcome after 10 years. Stereotact Funct Neurosurg 92:381-387, 2014

5. Kocabicak E, Aygun D, Ozaydin I, Jahanshahi A, Tan S, Onar M, Boke O, Kurt M, Guz H, Terzi M, Alptekin O, Temel Y: Does probe's eye subthalamic nucleus length on T2W MRI correspond with microelectrode recording in patients with deep brain stimulation for advanced Parkinson's disease? Turk Neurosurg 23:658-665, 2013

6. Kocabicak E, Temel Y: Deep brain stimulation of the subthalamic nucleus in Parkinson's disease: Surgical technique, tips, tricks and complications. Clin Neurol Neurosurg 115:2318-2323, 2013

7. Littlechild P, Varma TR, Eldridge PR, Fox S, Forster A, Fletcher N, Steiger M, Byrne P, Tyler K, Flintham S: Variability in position of the subthalamic nucleus targeted by magnetic resonance imaging and microelectrode recordings as compared to atlas coordinates. Stereotact Funct Neurosurg 80:82-87, 2003

8. Liu Y, Li W, Tan C, Liu X, Wang X, Gui Y, Qin L, Deng F, Hu C, Chen $\mathrm{L}$ : Meta-analysis comparing deep brain stimulation of the globus pallidus and subthalamic nucleus to treat advanced Parkinson disease. J Neurosurg 121:709-718, 2014

9. Massey LA, Miranda MA, Zrinzo L, Al-Helli O, Parkes HG, Thornton JS, So PW, White MJ, Mancini L, Strand C, Holton JL, Hariz MI, Lees AJ, Revesz T, Yousry TA: High resolution MR anatomy of the subthalamic nucleus: Imaging at $9.4 \mathrm{~T}$ with histological validation. Neuroimage 59:2035-2044, 2012

10. Mavridis I, Boviatsis E, Anagnostopoulou S: Anatomy of the human subthalamic nucleus: A combined morphometric study. Anat Res Int 2013:319710, 2013

11. Molinuevo JL, Valldeoriola F, Valls-Sole J: Usefulness of neurophysiologic techniques in stereotactic subthalamic nucleus stimulation for advanced Parkinson's disease. Clin Neurophysiol 114:1793-1799, 2003

12. Patil PG, Conrad EC, Aldridge JW, Chenevert TL, Chou KL: The anatomical and electrophysiological subthalamic nucleus visualized by $3-T$ magnetic resonance imaging. Neurosurgery 71:1089-1095; discussion 1095, 2012
13. Priori A, Egidi $M$, Pesenti $A$, Rohr $M$, Rampini $P$, Locatelli $M$, Tamma F, Caputo E, Chiesa V, Barbieri S: Do intraoperative microrecordings improve subthalamic nucleus targeting in stereotactic neurosurgery for Parkinson's disease? J Neurosurg Sci 47:56-60, 2003

14. Romanelli P, Bronte-Stewart H, Heit G, Schaal DW, Esposito V: The functional organization of the sensorimotor region of the subthalamic nucleus. Stereotact Funct Neurosurg 82:222-229, 2004

15. Rothlind JC, York MK, Carlson K, Luo P, Marks WJ, Jr., Weaver FM, Stern M, Follett K, Reda D: Neuropsychological changes following deep brain stimulation surgery for Parkinson's disease: Comparisons of treatment at pallidal and subthalamic targets versus best medical therapy. J Neurol Neurosurg Psychiatry 86(6):622-629, 2015

16. Savas A, Akbostanci C, Yagmurlu B, Elibol B, Erden I, Kanpolat Y: A new method for subthalamic nucleus targeting using CT/MRI image-fusion technology. Acta Neurochir 144:1076-1077, 2002

17. Savas A, Bozkurt M, Akbostanci C: A comparison between stereotactic targeting methods of the subthalamic nucleus in cases with Parkinson's disease. Acta Neurochir Suppl 117:35-41, 2013

18. Schlaier JR, Habermeyer C, Warnat J, Lange $M$, Janzen A, Hochreiter A, Proescholdt M, Brawanski A, Fellner C: Discrepancies between the MRI-and the electrophysiologically defined subthalamic nucleus. Acta Neurochir (Wien) 153:23072318, 2011

19. Schuepbach WM, Rau J, Knudsen K, Volkmann J, Krack P, Timmermann L, Halbig TD, Hesekamp H, Navarro SM, Meier N, Falk D, Mehdorn M, Paschen S, Maarouf M, Barbe MT, Fink GR, Kupsch A, Gruber D, Schneider GH, Seigneuret E, Kistner A, Chaynes P, Ory-Magne F, Brefel Courbon C, Vesper J, Schnitzler A, Wojtecki L, Houeto JL, Bataille B, Maltete D, Damier P, Raoul S, Sixel-Doering F, Hellwig D, Gharabaghi A, Kruger R, Pinsker MO, Amtage F, Regis JM, Witjas T, Thobois S, Mertens P, Kloss M, Hartmann A, Oertel WH, Post B, Speelman H, Agid Y, SchadeBrittinger C, Deuschl G: Neurostimulation for Parkinson's disease with early motor complications. N Engl J Med 368:610-622, 2013

20. Slavin KV, Thulborn KR, Wess $\mathrm{C}$, Nersesyan H: Direct visualization of the human subthalamic nucleus with 3T MR imaging. AJNR Am J Neuroradiol 27:80-84, 2006

21. Temel $Y$, Wilbrink P, Duits A, Boon P, Tromp S, Ackermans L, van Kranen-Mastenbroek V, Weber W, Visser-Vandewalle V: Single electrode and multiple electrode guided electrical stimulation of the subthalamic nucleus in advanced Parkinson's disease. Neurosurgery 61:346-355; discussion 355-357, 2007

22. Visser-Vandewalle $V$, van der Linden $C$, Temel $Y$, Celik $H$, Ackermans L, Spincemaille G, Caemaert J: Long-term effects of bilateral subthalamic nucleus stimulation in advanced Parkinson disease: A four year follow-up study. Parkinsonism Relat Disord 11:157-165, 2005

23. Xiao Y, Beriault S, Pike GB, Collins DL: Multicontrast multiecho FLASH MRI for targeting the subthalamic nucleus. Magn Reson Imaging 30:627-640, 2012

24. Zaidel A, Spivak A, Grieb B, Bergman H, Israel Z: Subthalamic span of beta oscillations predicts deep brain stimulation efficacy for patients with Parkinson's disease. Brain 133:2007-2021, 2010 